\title{
Biomarkers for osteoarthritis: investigation, identification, and prognosis
}

This article was published in the following Dove Press journal:

Current Biomarker Findings

30 June 2012

Number of times this article has been viewed

\author{
Guangju Zhai ${ }^{1,2}$ \\ Erfan Aref Eshghi' \\ 'Faculty of Medicine, Memorial \\ University of Newfoundland, St John's, \\ NL, Canada; ${ }^{2}$ Department of Twin \\ Research and Genetic Epidemiology, \\ King's College London, London, UK
}

Correspondence: Guangju Zhai Discipline of Genetics, Faculty of Medicine, Memorial University of Newfoundland, 300 Prince Philip Drive, St John's, NL AIB 3V6, Canada

Tel +I 7097777286

Fax + I 7097777497

Email guangju.zhai@med.mun.ca

\begin{abstract}
Osteoarthritis (OA) is the most common form of arthritis and results in substantial morbidity and disability in the elderly, imposing a great economic burden on society. While there are drugs available on the market that mitigate pain and improve function, there are no disease-modifying osteoarthritis drugs, partly because there is no reliable method that can be used to identify early OA changes. There is a pressing need to develop reliable biomarkers that can inform on the process of joint destruction in OA. Such biomarkers could aid in drug development by identifying fast progressors and detecting early response to therapy, thus reducing patient numbers and time required for clinical trials. Over the last several years, dramatic advances in our understanding of the biochemistry of cartilage have led to a cascade of studies testing proteins as biomarkers of OA. Investigation of single-nucleotide polymorphisms as genetic biomarkers and the application of technologies such as metabolomics to OA are generating potentially additional biomarkers that could help detect early OA changes. This review summarizes the data on the investigation of biochemical and genetic markers in OA and highlights the new biomarkers that are recently reported and their application and limitation in the management of OA. However, despite the dramatic growth of knowledge concerning the discovery of a number of useful biomarkers, the real breakthrough in this area is still not achieved.
\end{abstract}

Keywords: osteoarthritis, biochemical markers, metabolomics, genetics, epigenetics

\section{Introduction}

Osteoarthritis (OA) is characterized pathologically by focal areas of damage to the articular cartilage, centered on load-bearing areas, associated with new bone formation at the joint margins (osteophytosis), changes in the subchondral bone, variable degrees of mild synovitis, and thickening of the joint capsule. ${ }^{1}$ It primarily involves the joints of the knee, hip, spine, hand, and foot, is strongly associated with increasing age, and affects approximately twice as many females as males. It is the most common form of arthritis, results in substantial morbidity and disability in the elderly, ${ }^{2}$ and imposes a great economic burden on society. ${ }^{3}$ This societal burden (both in terms of personal suffering and use of health resources) is expected to increase worldwide with the increasing prevalence of obesity and the aging of the community. ${ }^{4}$

Despite high prevalence and societal impact, OA is far behind other skeletal diseases like osteoporosis in the availability of disease-modifying treatments. This is mainly because little is known about the underlying molecular mechanisms that could be exploited by therapeutic targets. ${ }^{5}$ Further, this is compounded by the inability to detect early OA changes by current evaluation methods. 
Plain radiography has been by far the standard diagnostic method in OA; however, it is insufficient to determine the progression and outcome of new treatments in short timescales due to their semiquantitative grading scale and low sensitivity. Furthermore, OA changes that can be observed on X-rays are usually in more advanced stage of the disease, in which joint tissue damage is considered irreversible. Magnetic resonance imaging has the ability to visualize simultaneously all joint tissues and has been increasingly used in OA research studies, but the parameters that can be used for early diagnosis and clinical trials are still unclear. ${ }^{6}$

The field of OA study is desperately in need of biomarkers, as highlighted by the OA Biomarkers Global Initiative. A sound biomarker is OA-specific, reflects actual disease development and progression, facilitates earlier diagnosis, is sensitive to changes due to therapeutic intervention, and can predict disease outcome. Biomarkers are generally considered to be biological substances, although some researchers view imaging and even traditional disease risk factors as biomarkers. In this review, we shall consider only biological substances, which include genetic (DNA and RNA) and biochemical (carbohydrate, proteins, proteins fragments, peptides, metabolites) molecules. We shall summarize the data on the investigation of biochemicals and genetics in OA, and highlight new biomarkers that have been reported recently and their application and limitations in the management of OA.

\section{Biochemical markers}

Progressive loss of articular cartilage is a central feature of OA. Articular cartilage, a nonvascular tissue, is composed of chondrocytes embedded in an extracellular matrix (ECM), which provides the biomechanical and physiologic characteristics that are essential for articular movement. ${ }^{7}$ Type II collagen (CII) provides the major portion of the organic components $(15 \%-22 \%)$ in the ECM, followed by aggrecan $(4 \%-7 \%)$, and other noncollagenous proteins $(0.5 \%-1 \%)$, including cartilage oligomeric matrix protein. ${ }^{8}$ Because an imbalance in cartilage synthesis and degradation is central to cartilage loss in OA, biomarkers reflecting these metabolic processes in the ECM have been under extensive investigation.

So far, there are eight biochemical markers concerning CII metabolism. Six of them are for CII degradation (CTX-II, Helix-II, C2C, Coll2-1, Coll2-1 $\mathrm{NO}_{2}$, TIINE) and two for CII synthesis (PIIANP, PIICP). ${ }^{9}$ Among them, CTX-II was investigated most extensively despite its known limitations in that its tissue origins remain ambiguous ${ }^{10}$ and the immunoreactive epitope is not well characterized. ${ }^{11}$ Owing to its small size, it is freely filtered by the renal system and is concentrated in the urine. ${ }^{12}$ Urinary (u) CTX-II correlates well with the total body burden of osteophytes and satisfies four categories of the burden of disease, investigative, prognostic, efficacy of intervention, diagnosis of the disease, and safety of intervention (BIPED) classification scheme. ${ }^{13}$ Coll2-1 is a good disease-specific marker that is sensitive to the structural changes occurring in a single joint. ${ }^{14}$ Coll2-1 and Coll2-1 $\mathrm{NO}_{2}$ are useful for studying oxidative-related CII network degradation in OA. ${ }^{15}$ Of note, Helix-II might originate from type III collagen, rather than from CII, as thought previously. ${ }^{16}$

Aggrecan is a major proteoglycan found in the ECM and largely responsible for the high resistance to compression of this load-bearing tissue. ${ }^{7}$ Aggrecan depletion in OA cartilage can be ascribed to increased proteolytic cleavage of the core protein and is mediated by various matrix proteinases. ${ }^{7}$ Detection of aggrecanase-cleaved fragments of aggrecan in human serum and urine has been developed, ${ }^{17,18}$ but hard data are still very scant.

Cartilage oligomeric matrix protein (COMP) is a tissuespecific matrix thrombospondin-family protein that is synthesized by chondrocytes. ${ }^{19}$ It is abundant in OA cartilage, and can also be measured in serum and synovial fluids. Its concentration is ten times higher in synovial fluids than in serum, indicating preferential release from the affected joints. However, precisely what role it plays in OA pathogenesis remains unclear. ${ }^{20}$ It is the second most studied OA biomarker and satisfies four categories of BIPED. It is worthy to mention that analysis of the data, including a series of potential biomarkers measured on 137 patients with symptomatic knee OA in the Boston Osteoarthritis of the Knee Study, showed that among the six biomarker studies $(\mathrm{C} 1-2 \mathrm{C}, \mathrm{C} 2 \mathrm{C}$, C-propeptide, Col2CTx, Aggrecan 846 epitope, and COMP), COMP was the only marker that was a statistically significant predictor of cartilage loss even after adjustment for age, gender, and BMI. ${ }^{21}$

Further, OA is widely accepted as a disease of the whole joint affecting not only the cartilage but also the subchondral bone and the synovial membrane. Changes in these structures were found to be related to the disease and an interesting target in OA biomarker research. However, biomarkers derived from these tissues have received far less attention in the context of OA than the biomarkers from cartilage.

Hyaluronic acid, also known as hyaluronan (HA) is a glycosaminoglycan formed by alternating units of glucosamine and glucuronic acid. ${ }^{22}$ It is a constituent of synovium and 
cartilage, and is thought to contribute to the lubricating mechanisms of synovial fluid. HA concentration can be measured in synovial fluid and serum. Serum HA levels correlate positively with total osteophyte burden after adjustment for age, weight, and height, ${ }^{13}$ is the third most studied OA biomarker, and satisfies four categories of BIPED.

Degradation of type I collagen during subchondral bone resorption can be reflected by elevated levels of $\mathrm{N}$ - and C-terminal cross-linked telopeptides (NTX-I and CTX-I). Berry et $\mathrm{a}^{23}$ found that both CTX-I and NTX-I were significantly associated with reduced cartilage loss. Bettica et $\mathrm{al}^{24}$ found that these two bone resorption markers were significantly associated with progressive OA patients, but there was no difference between healthy and nonprogressive OA subjects. However, these conclusions are probably not unequivocal. A review suggested that biochemical markers of bone metabolism performed less adequately in comparison to cartilage and synovium factors. ${ }^{9}$

Other less investigated OA biochemical markers include type I collagen synthesis (PICP, PINP), collagen type III synthesis (PIIINP), collagen type I and II degradation $(\mathrm{C} 1,2 \mathrm{C})$, osteocalcin, bone sialoprotein, keratin sulphate, chondroitin sulphate 846 (CS846), human glycoprotein of cartilage 39 (YKL-40), collagen cross-links (pyridinoline [Pyr], deoxypyridinoline [D-Pyr], glucosyl-galactosyl pyridinoline [Glc-Gal-Pyr]), and pentosidine. Information on the molecular basis of the aforementioned biochemical markers is described in the comprehensive review by Garnero et al in $2000,{ }^{22}$ and a detailed review on the investigation of these biochemical markers has been provided by Livshits et al. ${ }^{25}$

The performance of a biomarker is characterized by sensitivity and specificity, or positive and negative predictive values. A biomarker for clinical use needs to have a good sensitivity of 0.9 or higher, and a good specificity of 0.9 or higher. ${ }^{26}$ However, most of these biochemical OA markers do not have data on their predictive capability yet. The data on the two most investigated markers - CTX-II and COMP - show that they do not have such a predictive capability for clinical use. ${ }^{27,28}$ Animal model data ${ }^{29}$ and results from a pilot human study using risedronate, a bisphosphonate, showed that urine levels of CTX-II were dramatically decreased by risedronate treatment, together with expected decreases on bone turnover marker levels. ${ }^{30}$ These results were confirmed in a large randomized clinical trial of knee OA. ${ }^{31}$ However, neither knee joint structure as monitored by standardized radiographs nor symptoms were affected by risedronate treatment over 2 years. ${ }^{31}$ These results suggested that CTX-II failed as a biomarker to reflect efficacy of response in clinical trials. On the other hand, the majority of these biomarkers were investigated using radiographic $\mathrm{OA}$ as an end-point measure, making it difficult to judge their usefulness in early diagnosis of the disease. A recent study ${ }^{32}$ examined 14 biomarkers (uCTX-II, uCTX-I, uNTX-I, sCOMP, sPIIANP, sCS846, sC1, 2C, sOC, sPINP, sHA, sPIIINP, pLeptin, pAdiponectin, pResistin) in a 10-year prospective cohort of 1002 individuals with early symptomatic knee and/or hip OA. Using principal component analysis, the authors identified five clusters of interrelated biomarkers within the biomarker spectrum, consecutively designated as "bone-CTX-II," "inflammation," "synovium," "C1, 2C-adipokines," and "cartilage synthesis" clusters. The identified clusters extended knowledge on individual biomarkers, suggesting the potential of combined biomarkers in early diagnosis of OA.

\section{Novel biomarkers by a metabolomics approach}

There is mounting evidence that OA may also be a "metabolic disorder," as lipid, metabolic, and humoral factors appear to contribute to the initiation and progression of OA. ${ }^{33}$

Metabolomics is a state-of-the-art technique that allows a large number of small-molecule metabolites from body fluids or tissues to be detected quantitatively in a single step, and promises immense potential for early diagnosis, therapy monitoring, and understanding the origin and development of many diseases. The method has proved very useful in the rapid assessment of several disease states, such as diabetes, ${ }^{34,35}$ coronary heart disease, ${ }^{36}$ and blood pressure ${ }^{37}$

Application of the metabolomics approach in OA biomarker discovery is emerging. Williamson et $\mathrm{al}^{38}$ studied the levels of a range of components measured by ${ }^{1} \mathrm{H}$ NMR in samples of synovial fluid taken from three groups of patients comprising ten with OA, 18 with rheumatoid arthritis (RA), and eleven with traumatic effusions. They found that patients with traumatic effusions had high levels of saturated triglycerides, while those with OA had low levels. The chain length of the triglycerides found in OA synovial fluid appears to be shorter than that for the other groups. Lamers et $\mathrm{al}^{39}$ studied urine samples of 47 non-OA controls and 45 individuals with radiographic OA of the knees or hips. They showed that urine NMR spectra can discriminate OA cases and controls in both males and females, and the metabolic profiles largely resembled the profile identified in the guinea pig model. ${ }^{40}$ They also demonstrated a high correlation between Kellgren-Lawrence score and the metabolite profile with $R^{2}=0.82-0.93$. 
Recently, using the targeted metabolomic approach, we studied 163 serum metabolites in a discovery sample of 123 knee OA cases and 299 controls from the TwinsUK cohort and a replication sample of 76 knee OA cases and 100 controls from the Chingford Study. We identified 14 metabolite ratios that were significantly associated with knee OA in the TwinsUK cohort. Two of these 14 metabolite ratios were confirmed in the Chingford Study as correlating with knee OA: the ratio of branched-chain amino acids to histidine. ${ }^{41}$ The findings are supported by other animal and human data. An animal model of osteoarthritis showed an enhancement of the resonance at $0.85 \mathrm{ppm}$ of the ${ }^{1} \mathrm{H}$ high-resolution magicangle spinning NMR spectra of the osteoarthritis-affected cartilage sample, which could be attributable to the increase in leucine and isoleucine. ${ }^{42} \mathrm{~A}$ recent study ${ }^{43}$ obtained metabolic profiles of synovial tissue cultures from patients with end-stage OA or from control individuals. The researchers identified 105 distinct compounds, and concentrations of eleven of these biochemicals were markedly different between the samples from patients with OA and those from controls. Although metabolic profiles from the cultured tissues may not be expected to reproduce in vitro profiles, the study confirms that potential biomarkers of OA could be involved in cellular metabolic and energetic processes such as branched-chain amino acid catabolism and support our findings. ${ }^{41}$

These results are still preliminary in terms of clinical use, and further characterization is needed, with their predictive capability to be assessed. However, these studies highlight the potential of metabolomic analyses to provide an alternative perspective of the altered biochemical processes responsible for OA onset and/or progression. ${ }^{44}$

\section{Genetic markers}

Evidence suggests that genetic factors play a major role in OA, although they may be site- and sex-specific. From twin studies, this genetic influence has been estimated to be between $40 \%$ and $65 \%,{ }^{45,46}$ and first-degree relatives have a two- to threefold increased risk of disease. ${ }^{47,48}$ The nature of the genetic influence in $\mathrm{OA}$ is still unclear, but is likely to involve a combination of effects on structure (ie, collagen), alterations in cartilage, or bone metabolism or inflammation. ${ }^{49}$ It is believed that identification of specific genetic factors for OA can help our understanding in the pathogenesis of OA and identify people and families with high risk for OA earlier.

Numerous efforts have been made at great expense on human genetic studies on OA worldwide. Several linkage scans have been performed and identified large chromosome regions associated with $\mathrm{OA},{ }^{50-54}$ but these are of limited value for detecting any specific susceptible genes. A number of candidates have been reported with OA, although many early studies were based on small numbers and were not replicated. One of the most consistent has been the vitamin $\mathrm{D}$ receptor gene (a candidate gene for osteoporosis), although size and direction of results differed when subjects were defined by osteophytes or joint space ${ }^{55,56}$ or site of OA. ${ }^{57}$ Another potential candidate related to bone is transforming growth factor- $\beta$, and an association with disk degeneration. ${ }^{58}$ A single-nucleotide polymorphism (SNP) (rs12901499) mapping to intron 1 of $S M A D 3$, a key intracellular messenger in the transforming growth factor- $\beta$ signaling pathway, was associated with both knee and hip OA. ${ }^{59}$ Lumbar disk degeneration has also been associated with mutations in the gene for collagen type IX in the Finnish population. ${ }^{60}$ Other candidate genes include estrogen receptor genes, aggrecan, CRTL1, TNF, and the interleukin (IL)-1 gene cluster, which has been validated in several populations of knee OA. ${ }^{61}$ Another is the gene $F R Z B$, implicated in linkage studies and associated in females with hip OA. ${ }^{62} \mathrm{FRZB}$ was also found to be associated with knee OA in women but not men. ${ }^{63} \mathrm{DIO} 2$ is a regulator of thyroid hormone metabolism in the growth plate and may confer susceptibility for OA at multiple joint sites, as suggested in a linkage study. ${ }^{64}$ Valdes et al showed an association with specific candidates with progression of knee OA, which given that OA is nearly universal in the elderly, may be a more revealing phenotype. The genes implicated were $A D A M 12, C I L P, O P G$, and $T N A .{ }^{65}$ These genes have recently been replicated in an independent sample with clinical knee OA. ${ }^{66}$ A convincing association study has been performed in Japanese patients, where the gene that encodes for asporin - ASPN - an extracellular matrix protein, was associated in two populations with knee OA. ${ }^{67}$ A meta-analysis suggested that an $A S P N$ allele is protective against the risk of knee OA in Caucasians. ${ }^{63}$ Spector et al reported that the gene leucine-rich repeats and calponin homology containing 1 ( $\mathrm{LRCH1}$ ) was consistently associated with knee OA in three samples of pooled DNA from two populations with northern European ancestry, ${ }^{68}$ but this has not been replicated independently ${ }^{69}$ Using 2170 patients with OA and 2849 controls, Valdes et al found three SNPs in the $A N P 32 A$ gene were significantly associated in hip OA, but not knee $\mathrm{OA} .^{70}$ The most convincing and robust association was a single SNP (rs143383, T/C) located in the $5^{\prime}$-UTR of the GDF5 gene, which was reported in Japanese and Chinese case-control cohorts. ${ }^{71}$ The major T allele of the SNP was 
common in Asian populations, with frequencies $>70 \%$ in controls, and was at an elevated frequency in OA cases, with odds ratios ranging from 1.30 to 1.79 for knee and hip cases. The same $\mathrm{T}$ allele was found to be increased in hip and knee OA cases from Spain and the UK relative to controls with a very modest odds ratio of $1.10 .^{72,73}$

However, all these previous candidate gene studies have to be interpreted with extreme caution, as most are likely to be false positives. ${ }^{74}$ Large meta-analyses of published candidates in diabetes ${ }^{75}$ and osteoporosis ${ }^{76}$ have suggested that less than $10 \%$ of reported published associations are real. However, a large meta-analysis from the TreatOA consortium did confirm the association of the gene GDF5 but not $F R Z B$, despite many publications on the latter. ${ }^{72}$

Genome-wide association study (GWAS) is a powerful approach for unlocking the genetic basis of complex diseases such as OA. The method has uncovered $>800$ SNP associations for more than 150 disease and other traits. ${ }^{77}$ Notable advantages include its comprehensiveness and the potential for finding susceptibility genes with previously unknown loci and relationship to the diseases.

The first wave of GWAS in OA has been published. While these studies clearly show that there is no definitive and common highly penetrant allele that causes OA, some interesting candidate genes emerged from these studies.

To date, five large case-control association scans have been reported. Mototani and coworkers ${ }^{78}$ tested 72,000 markers for association with hip OA, and identified a variant in the CALM1 gene to be strongly associated in the Japanese population. However, studies in United Kingdom samples failed to show an association of this variant with hip ${ }^{79}$ or knee OA. ${ }^{63}$ A pooled, large-scale (500,000 markers) GWAS on knee OA has been published. ${ }^{80}$ The variants identified by this scan, although not achieving genome-wide significance $\left(P<5 \times 10^{-8}\right)$, have been subsequently replicated in independent cohorts, and fell in the $5^{\prime}$ region of the gene encoding the $C O X-2$ and the cytosolic phospholipase enzymes (both involved in prostaglandin synthesis), in the 2 q33 linkage region, and near a gene involved in transcriptional repression of thyroid hormone receptors. Using a two-stage approach genome-wide association, we identified the SNP rs716508 located in the $A 2 B P 1$ gene was associated with hand radiographic OA. The same allele of the SNP was also associated with reduced bone density at both hip and lumbar spine, suggesting the potential mechanism of the gene in hand OA might be via effects on subchondral bone. ${ }^{81}$ Kerkhof et $\mathrm{al}^{82}$ performed a GWAS testing > 500,000 SNPs in 1341 OA cases and 3496 Caucasian controls from The Netherlands. SNPs associated with at least two OA phenotypes were analysed in 14,938 OA cases and approximately 39,000 controls. The minor allele of rs3815148 on chromosome 7q22 was associated with a 1.14-fold increased risk for knee and/or hand OA $\left(P=8 \times 10^{-8}\right)$, and also with increased risk for knee OA progression. The region encompasses six genes: $P R K A R 2 B$, HPB1, COG5, GPR22, DUS4L, and BCAP29. None of these are obvious candidates for OA susceptibility, and functional studies have so far failed to prioritize compellingly one over the others. ${ }^{83}$ arcOGEN $^{84}$ is a UK study that recently reported stage 1 of its GWAS, which involved a discovery sample of 3177 OA cases and 4894 controls. The strongest signals found were rs2277831 in MICAL3, rs11280 in C6orf130, and rs2615977 in COL11A1, but none of these hits reached a genome-wide significance.

However, to date, no single large genetic effect has been found. Rather, the increased risks for carrying a predisposing gene variant are likely to be modest (odds ratio less than 1.3), ${ }^{85,86}$ thus limiting their individual predictive capability for clinical use. However, combinations of large numbers of risk alleles may have diagnostic value. Valdes et $\mathrm{al}^{87}$ examined 36 SNPs in 17 candidate genes previously associated with OA in 603 knee OA cases who met American College of Rheumatology criteria and 596 age- and ethnicitymatched controls. The odds ratio for individuals in the top quartile of the genetic risk variable compared to those in the bottom quartile was found to be 8.68 (95\% confidence interval 5.20-14.49, $P<2 \times 10^{-16}$ ) for women and 5.06 (95\% confidence interval 3.10-8.27, $P<1 \times 10^{-10}$ ) for men, suggesting that the additive information from a number of genetic variants can predict a substantial proportion of the risk of knee OA.

\section{Epigenetic markers}

Epigenetics encompasses changes to marks on the genome that are copied from one cell generation to the next, which may alter gene expression but do not involve changes in the primary DNA sequence. These marks include DNA methylation, histone modifications, and noncoding RNAs. Epigenetic patterns undergo dynamic changes during development, cell differentiation, and in response to environmental stimuli, leading to changes in temporal and spatial gene expression. Alteration in epigenetic state has been correlated with cancers ${ }^{88-93}$ and several other complex diseases. ${ }^{94-97}$ A recent genome-wide DNA methylation study ${ }^{88}$ on bladder cancer not only found that methylation of $T B X 2, T B X 3, G A T A 2$, and ZIC4 was associated with progression to muscle-invasive disease in pTa tumors but also demonstrated that methylation 
of $T B X 2$ alone has a sensitivity of $100 \%$, a specificity of $80 \%$, a positive predictive value of $78 \%$, and a negative predictive value of $100 \%$, with an area under the curve of 0.96 for predicting progression, suggesting DNA methylation markers have great potential to serve as useful biomarkers for disease prognosis.

Data on epigenetics in OA are still sparse. Poschl et $\mathrm{al}^{98}$ investigated whether the loss of aggrecan expression in OA was linked to methylation changes in the promoter by studying eleven normal (age 60-90 years) and six OA cases (age 62-79 years), but were unable to find an association. Roach et al $^{99}$ studied cartilage tissues obtained from the femoral heads of 16 patients with OA and ten control patients with femoral neck fracture to investigate whether the abnormal expression of matrix metalloproteinases $M M P-3,-9$, and -13 and ADAMTS-4 is associated with epigenetic unsilencing. They found that the overall percentage of nonmethylated sites was increased in OA patients (48.6\%) compared with controls (20.1\%): $20 \%$ versus $4 \%$ for $M M P-13,81 \%$ versus $47 \%$ for $M M P-9,57 \%$ versus $30 \%$ for $M M P-3$, and $48 \%$ versus $0 \%$ for $A D A M T S-4$. Cheung et al ${ }^{100}$ further demonstrated that the abnormal expression of $A D A M T S-4$ in OA chondrocytes corresponds to a heritable loss of DNA methylation at some $\mathrm{CpG}$ sites in the proximal promoter region of $A D A M T S-4$. Niu et al ${ }^{101}$ and Iliopoulos et $\mathrm{al}^{102}$ found that leptin expression level was different between $\mathrm{OA}$ and controls and demethylation of leptin promoter region might upregulate leptin gene expression level and contribute to OA. Hashimoto et al ${ }^{103}$ found that demethylation at the specific $\mathrm{CpG}$ sites in the $I L-1 \beta$ promoter in response to inflammatory cytokines in human articular chondrocytes results in long-term induction of $I L-1 \beta$. Scott et $\mathrm{al}^{104}$ showed that a reduction of superoxide dismutase 2 is associated with early stage of OA, and the superoxide dismutase 2 promoter had significant DNA methylation alteration in OA cartilage. Expression of the gene $G D F 5$, which is consistently reported to be associated with OA across populations, is found to be modulated epigenetically by DNA methylation. ${ }^{105}$

Further studies are needed to confirm these results and examine their potential value as diagnostic and prognostic biomarkers in OA. Also, large-scale studies should be initiated to examine the DNA methylation patterns in OA, systematically using recent advanced genomic technologies.

Small noncoding RNAs, known as miRNAs - short ( 21 nucleotides) single-stranded RNA molecules - play an important role in post-transcriptional regulation of gene expression. ${ }^{106}$ There are approximately 1000 miRNAs in the human genome, ${ }^{107}$ some of which are tissue-specific. ${ }^{108}$ Since extracellular miRNAs are detectable in most body fluids and excretions and they are resistant against factors like enzymes and freezing, they might be considered promising diagnostic markers for diseases. ${ }^{109}$

Several miRNAs are found to be differentially expressed between normal and osteoarthritic cartilage. ${ }^{83}$ Increased expression levels of miR-9 and miR-98 and decreased levels of miR-146, miR-27b, and miR-140 have been reported in OA cartilage. ${ }^{110-113} \mathrm{miR}-140$ was found to be expressed only in cartilaginous tissues in developing zebrafish ${ }^{114}$ and in murine skeletal development. ${ }^{115}$ In humans, the expression of miR-140 increases during chondrogenesis and is more abundant in articular cartilage, but reduced in OA. ${ }^{116-118}$ However, most of these studies are on animal models or in vitro, and population-based data are still sparse. Okuhara et $\mathrm{l}^{119}$ examined the expression patterns of miRNAs in the peripheral blood mononuclear cells of OA patients, and found that the relative expression levels of miR-146a, 155, 181a, and 223 in the OA patients were significantly higher than those found in healthy controls, suggesting these miRNAs might be related to the pathogenesis of OA. Murata et $\mathrm{al}^{120}$ found that synovial fluid concentrations of miR-16, 132, 146a, and 223 were significantly lower than their plasma concentrations in RA and OA patients, and there was no correlation between plasma and synovial fluid miRNAs. Plasma miR-132 differentiated healthy controls well from patients with RA and OA, while synovial fluid miRNAs differentiated RA and OA. Plasma miR-32 has a sensitivity of $84 \%$ and a specificity of $81.2 \%$ for OA diagnosis. These results are promising, and indicate the great potential value of miRNAs as biomarkers for OA.

\section{Conclusion}

A significant body of work on biomarkers of OA exists, and there is no doubt that it allows better understanding of the OA disease process. However, to date, none of these proposed biomarkers could be used in daily practice for diagnosing, monitoring, prognosticating, and clinical trials for OA, partly because of the lack of information about sensitivity, specificity, normal range, and clinically important differences. More research is needed to further characterize the previously identified biomarkers. Application of the latest state-of-the-art genomic and metabolomic technologies in novel OA biomarker discovery will help us not only in better understanding the pathophysiology of OA but also in the generation of a new wave of biomarkers. 


\section{Disclosure}

Financial support was received from the Research and Development Corporation of Newfoundland and Labrador Ignite Program, and the Cox Award, Faculty of Medicine, Memorial University of Newfoundland.

\section{References}

1. Paitzker K. Pathology of osteoarthritis. In: Brandt K, Doherty M, Lohmander LS, editors. Osteoarthritis, 2nd ed. Oxford: Oxford University Press; 2003:49-58.

2. World Health Organization. The Burden of Musculoskeletal Conditions at the Start of the New Millennium. Geneva: WHO; 2003.

3. Reginster JY. The prevalence and burden of arthritis. Rheumatology (Oxford). 2002;41(Suppl 1):3-6.

4. Bitton R. The economic burden of osteoarthritis. Am J Manag Care. 2009;15(Supp1 8):S230-S235.

5. Akune T, Kawaguchi H. Human genetic studies on osteoarthritis from clinicians' viewpoints. Osteoarthritis Cartilage. 2011;19(3): 251-253.

6. Teichtahl AJ, Wluka AE, Wang Y, Jones G, Ding C, Cicuttini FM. Identification of early knee osteoarthritis - a new horizon. Curr Rheumatol Rev. 2010;6(4):251-256.

7. Huang K, Wu LD. Aggrecanase and aggrecan degradation in osteoarthritis: a review. J Int Med Res. 2008;36(6):1149-1160.

8. Charni-Ben Tabassi N, Garnero P. Monitoring cartilage turnover. Current Rheumatol Rep. 2007;9(1):16-24.

9. van Spil WE, DeGroot J, Lems WF, Oostveen JC, Lafeber FP. Serum and urinary biochemical markers for knee and hip-osteoarthritis: a systematic review applying the consensus BIPED criteria. Osteoarthritis Cartilage. 2010;18(5):605-612.

10. Bay-Jensen AC, Andersen TL, Charni-Ben Tabassi N, et al. Biochemical markers of type II collagen breakdown and synthesis are positioned at specific sites in human osteoarthritic knee cartilage. Osteoarthritis Cartilage. 2008;16(5):615-623.

11. Patra D, Sandell LJ. Recent advances in biomarkers in osteoarthritis. Curr Opin Rheumatol. 2011;23(5):465-470.

12. Elsaid KA, Chichester CO. Review: Collagen markers in early arthritic diseases. Clin Chim Acta. 2006;365(1-2):68-77.

13. Kraus VB, Kepler TB, Stabler T, Renner J, Jordan J. First qualification study of serum biomarkers as indicators of total body burden of osteoarthritis. PLoS One. 2010;5(3):e9739.

14. Deberg M, Dubuc JE, Labasse A, et al. One-year follow-up of Coll2-1, Coll2-1 $\mathrm{NO}_{2}$ and myeloperoxydase serum levels in osteoarthritis patients after hip or knee replacement. Ann Rheum Dis. 2008;67(2):168-174.

15. Deberg M, Labasse A, Christgau S, et al. New serum biochemical markers (Coll 2-1 and Coll 2-1 $\mathrm{NO}_{2}$ ) for studying oxidative-related type II collagen network degradation in patients with osteoarthritis and rheumatoid arthritis. Osteoarthritis Cartilage. 2005;13(3):258-265.

16. Eyre DR, Weis MA. The Helix-II epitope: a cautionary tale from a cartilage biomarker based on an invalid collagen sequence. Osteoarthritis Cartilage. 2009;17(4):423-426.

17. Swearingen CA, Carpenter JW, Siegel R, et al. Development of a novel clinical biomarker assay to detect and quantify aggrecanasegenerated aggrecan fragments in human synovial fluid, serum and urine. Osteoarthritis Cartilage. 2010;18(9):1150-1158.

18. Dufield DR, Nemirovskiy OV, Jennings MG, Tortorella MD, Malfait AM, Mathews WR. An immunoaffinity liquid chromatographytandem mass spectrometry assay for detection of endogenous aggrecan fragments in biological fluids: use as a biomarker for aggrecanase activity and cartilage degradation. Anal Biochem. 2010;406(2):113-123.

19. Rousseau JC, Delmas PD. Biological markers in osteoarthritis. Nat Clin Pract Rheumatol. 2007;3(6):346-356.

20. Williams FM, Spector TD. Biomarkers in osteoarthritis. Arthritis Res Ther. 2008;10(1):101.
21. Hunter DJ, Li J, LaValley M, et al. Cartilage markers and their association with cartilage loss on magnetic resonance imaging in knee osteoarthritis: the Boston Osteoarthritis Knee Study. Arthritis Res Ther. 2007;9(5):R108

22. Garnero P, Rousseau JC, Delmas PD. Molecular basis and clinical use of biochemical markers of bone, cartilage, and synovium in joint diseases. Arthritis Rheum. 2000;43(5):953-968.

23. Berry PA, Maciewicz RA, Cicuttini FM, Jones MD, Hellawell CJ, Wluka AE. Markers of bone formation and resorption identify subgroups of patients with clinical knee osteoarthritis who have reduced rates of cartilage loss. J Rheumatol. 2010;37(6):1252-1259.

24. Bettica P, Cline G, Hart DJ, Meyer J, Spector TD. Evidence for increased bone resorption in patients with progressive knee osteoarthritis: longitudinal results from the Chingford study. Arthritis Rheum. 2002;46(12):3178-3184.

25. Livshits G, Ermakov S, Vilker A. Outlines of the biochemistry of osteoarthritis. Curr Rheumatol Rev. 2010;6(4):234-250.

26. Brower V. Biomarkers: portents of malignancy. Nature. 2011;471(7339): S19-S21.

27. Dam EB, Loog M, Christiansen C, et al. Identification of progressors in osteoarthritis by combining biochemical and MRI-based markers. Arthritis Res Ther. 2009;11(4):R115.

28. Sowers MF, Karvonen-Gutierrez CA, Yosef M, et al. Longitudinal changes of serum COMP and urinary CTX-II predict X-ray defined knee osteoarthritis severity and stiffness in women. Osteoarthritis Cartilage. 2009;17(12):1609-1614.

29. Bendele AM, Hulman JF. Spontaneous cartilage degeneration in guinea pigs. Arthritis Rheum. 1988;31(4):561-565.

30. Spector TD, Conaghan PG, Buckland-Wright JC, et al. Effect of risedronate on joint structure and symptoms of knee osteoarthritis: results of the BRISK randomized, controlled trial [ISRCTN01928173]. Arthritis Res Ther. 2005;7(3):R625-R633.

31. Garnero P, Aronstein WS, Cohen SB, et al. Relationships between biochemical markers of bone and cartilage degradation with radiological progression in patients with knee osteoarthritis receiving risedronate: the Knee Osteoarthritis Structural Arthritis randomized clinical trial. Osteoarthritis Cartilage. 2008;16(6):660-666.

32. van Spil WE, Jansen NW, Bijlsma JW, et al. Clusters within a wide spectrum of biochemical markers for osteoarthritis: data from CHECK, a large cohort of individuals with very early symptomatic osteoarthritis. Osteoarthritis Cartilage. Epub April 11, 2012.

33. Velasquez MT, Katz JD. Osteoarthritis: another component of metabolic syndrome? Metab Syndr Relat Disord. 2010;8(4):295-305.

34. Nicholson JK, O’Flynn MP, Sadler PJ, Macleod AF, Juul SM, Sonksen PH. Proton-nuclear-magnetic-resonance studies of serum, plasma and urine from fasting normal and diabetic subjects. Biochem J. 1984;217(2):365-375.

35. Griffin JL, Vidal-Puig A. Current challenges in metabolomics for diabetes research: a vital functional genomic tool or just a ploy for gaining funding? Physiol Genomics. 2008;34(1):1-5.

36. Brindle JT, Antti H, Holmes E, et al. Rapid and noninvasive diagnosis of the presence and severity of coronary heart disease using 1H-NMR-based metabonomics. Nat Med. 2002;8(12): 1439-1444.

37. Holmes E, Loo RL, Stamler J, et al. Human metabolic phenotype diversity and its association with diet and blood pressure. Nature. 2008;453(7193):396-400.

38. Williamson MP, Humm G, Crisp AJ. 1H nuclear magnetic resonance investigation of synovial fluid components in osteoarthritis, rheumatoid arthritis and traumatic effusions. Br J Rheumatol. 1989;28(1): 23-27.

39. Lamers RJ, van Nesselrooij JH, Kraus VB, et al. Identification of an urinary metabolite profile associated with osteoarthritis. Osteoarthritis Cartilage. 2005;13(9):762-768.

40. Lamers RJ, DeGroot J, Spies-Faber EJ, et al. Identification of diseaseand nutrient-related metabolic fingerprints in osteoarthritic Guinea pigs. J Nutr. 2003;133(6):1776-1780. 
41. Zhai G, Wang-Sattler R, Hart DJ, et al. Serum branched-chain amino acid to histidine ratio: a novel metabolomic biomarker of knee osteoarthritis. Ann Rheum Dis. 2010;69(6):1227-1231.

42. Borel M, Pastoureau P, Papon J, et al. Longitudinal profiling of articular cartilage degradation in osteoarthritis by high-resolution magic angle spinning 1H NMR spectroscopy: experimental study in the meniscectomized guinea pig model. J Proteome Res. 2009;8(5):2594-2600.

43. Adams SB Jr, Setton LA, Kensicki E, Bolognesi MP, Toth AP, Nettles DL. Global metabolic profiling of human osteoarthritic synovium. Osteoarthritis Cartilage. 2012;20(1):64-67.

44. Blanco FJ, Ruiz-Romero C. Osteoarthritis: metabolomic characterization of metabolic phenotypes in OA. Nature Reviews Rheumatology. 2012;8(3):130-132.

45. Zhai G, Hart DJ, Kato BS, Sharma L, Spector TD. Genetic contribution to knee radiographic osteoarthritis and knee alignment: a classical twin study. Arthritis Rheum. 2006;54(Suppl 9):S512.

46. Spector TD, Cicuttini F, Baker J, Loughlin J, Hart D. Genetic influences on osteoarthritis in women: a twin study. BMJ. 1996;312(7036): 940-943.

47. Hirsch R, Lethbridge-Cejku M, Hanson R, et al. Familial aggregation of osteoarthritis: data from the Baltimore Longitudinal Study on Aging. Arthritis Rheum. 1998;41(7):1227-1232.

48. Riyazi N, Meulenbelt I, Kroon HM, et al. Evidence for familial aggregation of hand, hip, and spine but not knee osteoarthritis in siblings with multiple joint involvement: the GARP study. Ann Rheum Dis. 2005;64(3):438-443.

49. Valdes AM, Spector TD. Genetic epidemiology of hip and knee osteoarthritis. Nat Rev Rheumatol. 2011;7(1):23-32.

50. Livshits G, Kato BS, Zhai G, et al. Genomewide linkage scan of hand osteoarthritis in female twin pairs showing replication of quantitative trait loci on chromosomes 2 and 19. Ann Rheum Dis. 2007;66(5):623-627.

51. Loughlin J, Mustafa Z, Irven C, et al. Stratification analysis of an osteoarthritis genome screen-suggestive linkage to chromosomes 4, 6 , and 16. Am J Hum Genet. 1999;65(6):1795-1798.

52. Ingvarsson T, Stefansson SE, Gulcher JR, et al. A large Icelandic family with early osteoarthritis of the hip associated with a susceptibility locus on chromosome 16p. Arthritis Rheum. 2001;44(11):2548-2555.

53. Chapman K, Mustafa Z, Dowling B, Southam L, Carr A, Loughlin J. Finer linkage mapping of primary hip osteoarthritis susceptibility on chromosome 11q in a cohort of affected sibling pairs. Arthritis Rheum. 2002;46(7):1780-1783.

54. Hunter DJ, Demissie S, Cupples LA, Aliabadi P, Felson DT. A genome scan for joint-specific hand osteoarthritis susceptibility: the Framingham Study. Arthritis Rheum. 2004;50(8):2489-2496.

55. Keen RW, Hart DJ, Lanchbury JS, Spector TD. Association of early osteoarthritis of the knee with a Taq I polymorphism of the vitamin D receptor gene. Arthritis Rheum. 1997;40(8):1444-1449.

56. Uitterlinden AG, Burger H, Huang Q, et al. Vitamin D receptor genotype is associated with radiographic osteoarthritis at the knee. J Clin Invest. 1997;100(2):259-263.

57. Jones G, White C, Sambrook P, Eisman J. Allelic variation in the vitamin D receptor, lifestyle factors and lumbar spinal degenerative disease. Ann Rheum Dis. 1998;57(2):94-99.

58. Yamada Y, Okuizumi H, Miyauchi A, Takagi Y, Ikeda K, Harada A. Association of transforming growth factor betal genotype with spinal osteophytosis in Japanese women. Arthritis Rheum. 2000;43(2):452-460.

59. Valdes AM, Spector TD, Tamm A, et al. Genetic variation in the SMAD3 gene is associated with hip and knee osteoarthritis. Arthritis Rheum. 2010;62(8):2347-2352.

60. Paassilta P, Lohiniva J, Goring HH, et al. Identification of a novel common genetic risk factor for lumbar disk disease. JAMA. 2001;285(14): 1843-1849.

61. Smith AJP, Keen LJ, Billingham MJ, et al. Extended haplotypes and linkage disequilibrium in the IL1R1-IL1A-IL1B-IL1RN gene cluster: association with knee osteoarthritis. Genes Immun. 2004;5(6):451-460.
62. Loughlin J, Dowling B, Chapman K, et al. Functional variants within the secreted frizzled-related protein 3 gene are associated with hip osteoarthritis in females. Proc Natl Acad Sci U S A. 2004;101(26): 9757-9762.

63. Valdes AM, Loughlin J, Oene MV, et al. Sex and ethnic differences in the association of ASPN, CALM1, COL2A1, COMP, and FRZB with genetic susceptibility to osteoarthritis of the knee. Arthritis Rheum. 2006;56(1):137-146.

64. Meulenbelt I, Min JL, Bos S, et al. Identification of DIO2 as a new susceptibility locus for symptomatic osteoarthritis. Hum Mol Genet. 2008;17(12):1867-1875.

65. Valdes AM, Hart DJ, Jones KA, et al. Association study of candidate genes for the prevalence and progression of knee osteoarthritis. Arthritis Rheum. 2004;50(8):2497-2507.

66. Valdes AM, Van Oene M, Hart DJ, et al. Reproducible genetic associations between candidate genes and clinical knee osteoarthritis in men and women. Arthritis Rheum. 2006;54(2):533-539.

67. Kizawa H, Kou I, Iida A, et al. An aspartic acid repeat polymorphism in asporin inhibits chondrogenesis and increases susceptibility to osteoarthritis. Nat Genet. 2005;37(2):138-144.

68. Spector TD, Reneland RH, Mah S, et al. Association between a variation in LRCH1 and knee osteoarthritis: a genome-wide single-nucleotide polymorphism association study using DNA pooling. Arthritis Rheum. 2006;54(2):524-532.

69. Jiang Q, Shi D, Nakajima M, et al. Lack of association of single nucleotide polymorphism in LRCH1 with knee osteoarthritis susceptibility. J Hum Genet. 2008;53(1):42-47.

70. Valdes AM, Lories RJ, van Meurs JB, et al. Variation at the ANP32A gene is associated with risk of hip osteoarthritis in women. Arthritis Rheum. 2009;60(7):2046-2054.

71. Miyamoto Y, Mabuchi A, Shi D, et al. A functional polymorphism in the $5^{\prime}$ UTR of GDF5 is associated with susceptibility to osteoarthritis. Nat Genet. 2007;39(4):529-533.

72. Evangelou E, Chapman K, Meulenbelt I, et al. Large-scale analysis of association between GDF5 and FRZB variants and osteoarthritis of the hip, knee, and hand. Arthritis Rheum. 2009;60(6):1710-1721.

73. Valdes AM, Spector TD, Doherty S, Wheeler M, Hart DJ, Doherty M. Association of the DVWA and GDF5 polymorphisms with osteoarthritis in UK populations. Ann Rheum Dis. 2009;68(12):1916-1920.

74. Limer KL, Tosh K, Bujac SR, et al. Attempt to replicate published genetic associations in a large, well-defined osteoarthritis casecontrol population (the GOAL study). Osteoarthritis Cartilage. 2009;17(6):782-789.

75. Goulart AC, Rexrode KM, Cheng S, et al. Association of genetic variants with the metabolic syndrome in 20,806 white women: the Women's Health Genome Study. Am Heart J. 2009;158(2):257-262.

76. Richards JB, Kavvoura FK, Rivadeneira F, et al. Collaborative metaanalysis: associations of 150 candidate genes with osteoporosis and osteoporotic fracture. Ann Intern Med. 2009;151(8):528-537.

77. Hindorff LA, Sethupathy P, Junkins HA, et al. Potential etiologic and functional implications of genome-wide association loci for human diseases and traits. Proc Natl Acad Sci U S A. 2009;106(23):9362-9367.

78. Mototani H, Mabuchi A, Saito S, et al. A functional single nucleotide polymorphism in the core promoter region of CALM1 is associated with hip osteoarthritis in Japanese. Hum Mol Genet. 2005;14(8):1009-1017.

79. Loughlin J, Sinsheimer JS, Carr A, Chapman K. The CALM1 core promoter polymorphism is not associated with hip osteoarthritis in a United Kingdom Caucasian population. Osteoarthritis Cartilage. 2006;14(3):295-298.

80. Valdes AM, Loughlin J, Timms KM, et al. Genome-wide association scan identifies a prostaglandin-endoperoxide synthase 2 variant involved in risk of knee osteoarthritis. Am J Hum Genet. 2008;82(6):1231-1240.

81. Zhai G, van Meurs JB, Livshits G, et al. A genome-wide association study suggests that a locus within the ataxin 2 binding protein 1 gene is associated with hand osteoarthritis: the Treat-OA consortium. J Med Genet. 2009;46(9):614-616. 
82. Kerkhof HJ, Lories RJ, Meulenbelt I, et al. A genome-wide association study identifies an osteoarthritis susceptibility locus on chromosome 7q22. Arthritis Rheum. 2010;62(2):499-510.

83. Reynard LN, Loughlin J. Genetics and epigenetics of osteoarthritis. Maturitas. 2012;71(3):200-204.

84. Panoutsopoulou K, Southam L, Elliott KS, et al. Insights into the genetic architecture of osteoarthritis from stage 1 of the arcOGEN study. Ann Rheum Dis. 2011;70(5):864-867.

85. Valdes AM, Evangelou E, Kerkhof HJ, et al. The GDF5 rs143383 polymorphism is associated with osteoarthritis of the knee with genome-wide statistical significance. Ann Rheum Dis. 2011;70(5): 873-875.

86. Evangelou E, Valdes AM, Kerkhof HJ, et al. Meta-analysis of genome-wide association studies confirms a susceptibility locus for knee osteoarthritis on chromosome 7q22. Ann Rheum Dis. 2011;70(2):349-355.

87. Valdes AM, Doherty M, Spector TD. The additive effect of individual genes in predicting risk of knee osteoarthritis. Ann Rheum Dis. 2008;67(1):124-127.

88. Kandimalla R, van Tilborg AA, Kompier LC, et al. Genome-wide analysis of $\mathrm{CpG}$ island methylation in bladder cancer identified TBX2, TBX3, GATA2, and ZIC4 as pTa-specific prognostic markers. Eur Urol. 2012;61(6):1245-1256.

89. Kulis M, Esteller M. DNA methylation and cancer. Adv Genet. 2010;70:27-56

90. Ting DT, Lipson D, Paul S, et al. Aberrant overexpression of satellite repeats in pancreatic and other epithelial cancers. Science. 2011;331(6017):593-596.

91. Feber A, Wilson GA, Zhang L, et al. Comparative methylome analysis of benign and malignant peripheral nerve sheath tumors. Genome Res. 2011;21(4):515-524.

92. Rawson JB, Manno M, Mrkonjic M, et al. Promoter methylation of Wnt antagonists DKK1 and SFRP1 is associated with opposing tumor subtypes in two large populations of colorectal cancer patients Carcinogenesis. 2011;32(5):741-747.

93. Kibriya MG, Raza M, Jasmine F, et al. A genome-wide DNA methylation study in colorectal carcinoma. BMC Med Genomics. 2011;4:50.

94. Javierre BM, Fernandez AF, Richter J, et al. Changes in the pattern of DNA methylation associate with twin discordance in systemic lupus erythematosus. Genome Res. 2010;20(2):170-179.

95. Nguyen A, Rauch TA, Pfeifer GP, Hu VW. Global methylation profiling of lymphoblastoid cell lines reveals epigenetic contributions to autism spectrum disorders and a novel autism candidate gene, RORA, whose protein product is reduced in autistic brain. FASEB J 2010;24(8):3036-3051.

96. Breitling LP, Yang R, Korn B, Burwinkel B, Brenner H. Tobacco-smoking-related differential DNA methylation: $27 \mathrm{~K}$ discovery and replication. Am J Hum Genet. 2011;88(4):450-457.

97. Almén MS, Jacobsson JA, Moschonis G, et al. Genome wide analysis reveals association of a FTO gene variant with epigenetic changes. Genomics. 2012;99(3):132-137.

98. Poschl E, Fidler A, Schmidt B, Kallipolitou A, Schmid E, Aigner T. DNA methylation is not likely to be responsible for aggrecan down regulation in aged or osteoarthritic cartilage. Ann Rheum Dis 2005;64(3):477-480.

99. Roach HI, Yamada N, Cheung KS, et al. Association between the abnormal expression of matrix-degrading enzymes by human osteoarthritic chondrocytes and demethylation of specific $\mathrm{CpG}$ sites in the promoter regions. Arthritis Rheumatism. 2005;52(10) 3110-3124.

100. Cheung KS, Hashimoto K, Yamada N, Roach HI. Expression of ADAMTS-4 by chondrocytes in the surface zone of human osteoarthritic cartilage is regulated by epigenetic DNA de-methylation. Rheumatol Int. 2009;29(5):525-534.
101. Niu SP, Huang CB, Zhao LK, Cheng YJ, Yang T. The role of promoter $\mathrm{CpG}$ islands methylation of leptin gene in osteoarthritis. Zhonghua Nei Ke Za Zhi. 2011;50(1):55-58. Chinese.

102. Iliopoulos D, Malizos KN, Tsezou A. Epigenetic regulation of leptin affects MMP-13 expression in osteoarthritic chondrocytes: possible molecular target for osteoarthritis therapeutic intervention. Ann Rheum Dis. 2007;66(12):1616-1621.

103. Hashimoto K, Oreffo RO, Gibson MB, Goldring MB, Roach HI. DNA demethylation at specific $\mathrm{CpG}$ sites in the IL1B promoter in response to inflammatory cytokines in human articular chondrocytes. Arthritis Rheum. 2009;60(11):3303-3313.

104. Scott JL, Gabrielides C, Davidson RK, et al. Superoxide dismutase downregulation in osteoarthritis progression and end-stage disease. Ann Rheum Dis. 2010;69(8):1502-1510.

105. Reynard LN, Bui C, Canty-Laird EG, Young DA, Loughlin J. Expression of the osteoarthritis-associated gene GDF5 is modulated epigenetically by DNA methylation. Hum Mol Genet. 2011;20(17):3450-3460.

106. Bartel DP. MicroRNAs: genomics, biogenesis, mechanism, and function. Cell. 2004;116(2):281-297.

107. Bentwich I, Avniel A, Karov Y, et al. Identification of hundreds of conserved and nonconserved human microRNAs. Nat Genet 2005;37(7):766-770

108. Lagos-Quintana M, Rauhut R, Yalcin A, Meyer J, Lendeckel W, Tuschl T. Identification of tissue-specific microRNAs from mouse. Curr Biol. 2002;12(9):735-739.

109. Barter MJ, Bui C, Young DA. Epigenetic mechanisms in cartilage and osteoarthritis: DNA methylation, histone modifications and microRNAs. Osteoarthritis Cartilage. 2012;20(5):339-349.

110. Jones SW, Watkins G, Le Good N, et al. The identification of differentially expressed microRNA in osteoarthritic tissue that modulate the production of TNF-alpha and MMP13. Osteoarthritis Cartilage. 2009;17(4):464-472.

111. Yamasaki K, Nakasa T, Miyaki S, et al. Expression of MicroRNA-146a in osteoarthritis cartilage. Arthritis Rheum. 2009;60(4):1035-1041.

112. Akhtar N, Rasheed Z, Ramamurthy S, Anbazhagan AN, Voss FR, Haqqi TM. MicroRNA-27b regulates the expression of matrix metalloproteinase 13 in human osteoarthritis chondrocytes. Arthritis Rheum. 2010;62(5):1361-1371.

113. Miyaki S, Sato T, Inoue A, et al. MicroRNA-140 plays dual roles in both cartilage development and homeostasis. Genes Dev. 2010;24(11):1173-1185.

114. Wienholds E, Kloosterman WP, Miska E, et al. MicroRNA expression in zebrafish embryonic development. Science. 2005;309(5732): 310-311

115. Tuddenham L, Wheeler G, Ntounia-Fousara S, et al. The cartilage specific microRNA-140 targets histone deacetylase 4 in mouse cells. FEBS Lett. 2006;580(17):4214-4217.

116. Tardif G, Hum D, Pelletier JP, Duval N, Martel-Pelletier J. Regulation of the IGFBP-5 and MMP-13 genes by the microRNAs miR-140 and miR-27a in human osteoarthritic chondrocytes. BMC Musculoskelet Disord. 2009;10:148.

117. Miyaki S, Nakasa T, Otsuki S, et al. MicroRNA-140 is expressed in differentiated human articular chondrocytes and modulates interleukin-1 responses. Arthritis Rheum. 2009;60(9):2723-2730.

118. Iliopoulos D, Malizos KN, Oikonomou P, Tsezou A. Integrative microRNA and proteomic approaches identify novel osteoarthritis genes and their collaborative metabolic and inflammatory networks. PLoS One. 2008;3(11):e3740.

119. Okuhara A, Nakasa T, Shibuya H, et al. Changes in microRNA expression in peripheral mononuclear cells according to the progression of osteoarthritis. Mod Rheumatol. Epub October 18, 2011.

120. Murata K, Yoshitomi H, Tanida S, et al. Plasma and synovial fluid microRNAs as potential biomarkers of rheumatoid arthritis and osteoarthritis. Arthritis Res Ther. 2010;12(3):R86. 


\section{Publish your work in this journal}

Current Biomarker Findings is an international, peer-reviewed, open access journal publishing original research, reports, reviews and commentaries on all areas of biomarker research. The manuscript management system is completely online and includes a very quick and fair peer-review system. Visit http://www.dovepress.com/testimonials.php to read real quotes from published authors. 